\title{
THE DIVINE LOGOS AND POSSIBLE WORLDS
}

\section{PhD. Walter GOMIDE}

\author{
Federal University of Mato Grosso. \\ Department of Philosophy, \\ BRAZIL \\ E-mail: waltergomide@yahoo.com
}

\begin{abstract}
In this paper I intend to show an attempt to translaeted into mathematics, especially into set theory and infinitary epistemic logic, the notion of "Divine Logos". From this translation, what is intended is to present the notion of metaphysical causality as strictly analogous to the epistemic implication and, with this, it attempts to provide a logical (and metaphysics) path that begins with Divine logos and terminates in the notion of the possible world. In this percourse, I am always pressuposing that God, by means of His "Divine Logos", knows every step of His creation, and this fact is explictly express by means of the last formula of this paper, namely, the expression. $n r$. 17. The inspiration for this construction comes from Leibniz's metaphysics and the theory of transfinite numbers of Georg Cantor, a german mathematician who is the founder of Theory of Sets.
\end{abstract}

Keywords: Divine Logos; Cantor; Leibniz;

\section{Introduction}

According to Leibniz, the world was created by God from a "choice of the best of possible worlds ${ }^{1}$." In fact, in God's mind all the worlds are present, that is, all the worlds reside in the thought of God in his completeness, in its fullness of actuality. Given this situation only comprehensible for divine intellection, God opts for one of these worlds and makes it real, in the sense that this world is the fruit of the divine option that becomes accessible to human experience: man, in his condition of epistemic agente, interacts with a reality that has come from the mind of God, and God chooses the physical world that surrounds us as the real world from unfathomable purposes to human reason. The only clue we have of this choice, according to Leibniz, is that such an option for this world over others has occurred because the world we live in is the best of the possible worlds.

But why is the surrounding physical world the best of all possible worlds? Perhaps for a reason of information economy, it is the world that God keeps active with the minimum energy necessary for its operation. Or, one might consider the physical world as one with the simplest structuring laws possible, and in this sense it would be the world with the least conceivable complexity ${ }^{2}$ Finally, the reasons that led God to choose this world and not another can be found through explanations that, to a certain extent, would appeal to the idea of a God operating in his creation with the greatest possible parsimony: God chooses a world

\footnotetext{
${ }^{1}$ See Leibniz, La Monadologie, $§ \S 53-55$, [1714]. English version: http://www.earlymoderntexts.com/assets/pdfs/leibniz1714b.pdf.

${ }^{2}$ See Chaitin, G: Complexity and Leibniz, IN: https://www.cs.auckland.ac.nz/ chaitin/tenerife.html.
} 
in that His performance does not have to occur at any moment; God chooses a world with the greatest possible autonomy, a world in which the need for miraculous interventions is minimal. In any case, God "chooses" the world that is the real, observable physical world, and this world is the "best" of them.

Perhaps in the opposite sense to the previous argument based on a God of parsimony and discreetness, the fact that this world is the best of all resides in the fact that it is the world that God loves the most and that is why God himself wants to intervene at all times, in an absurd and inexplicable way; perhaps this world is the place where epiphanies and more miracles happen and for this reason, based on the love of God, be the best possible.

But can we understand, schematically and narrowly, how the choice of the real world comes from an infinity of present worlds that reside in the mind of God? One point to be emphasized in this question is this: whatever the reasons that lead God to choose this world over others, God "chooses", that is, his action is free and as such is not determined by a process beyond his control. In other words, it is not possible to conceive of conditions of the will of God other than His purposes: God acts freely with unfathomable "strategies" to the human intellect. Therefore, whatever form we sketch the creation of the world, this form or way has to take into account the Divine freedom.

Let us consider, then, a scheme for the creation of the world inspired by the philosophy of the monads of Leibniz. Monads, in the leibnizian conception, are well-defined atoms of a spiritual nature which constitute the nature of things (LEIBNIZ, Monadolgy, § 1, [1714]).

One of the consequences of the simplicity inherent in the monads is their inexhaustible character. Since monads are simple points or the atoms of nature, then they have no extension, since extension is a characteristic of what is composed of parts, not of what is absolutely indivisible (LEIBNIZ, ibid). In this way, the monads are the simple elements of nature and have no extension. Therefore, the differentiation between one and the other is not then given by external factors such as the figure or the geometric form, but by an internal principle of activity. Each monad has an inner dynamism that is its own, and this dynamism generates an inner life that is characterized by perceptions and modifications; and it is this inner life, the appetite, which is different in each monad, the principle which imprints the monadic identity (ibid, §§ 7-11). In addition, monads organize themselves in such a way that some of them have more apperception or awareness of their perceptions, and others have less. However, it is good to be frize: every monad has an inner activity, its appetite, of which some are more or less conscious. In this sense, we can affirm that Leibniz endowed the constitutive atoms with the nature of activity, of dynamism, which is something in strict opposition to mechanicism that presupposed the physical world as a pure material extension obeying geometrical laws that do not take into account any kind of dynamism.

God creates an infinity of monads, and these come from God by fulgurations. In this way, the monads arise by God, and God is the primitive cause of all monads. Each monad owes its being to God, and God is the first monad from which all others arise by emanation or spreading (ibid., §47). Leibniz proposes a metaphysical configuration in which God creates the monads by continuous fulgurations. What seems to be suggested by Leibniz in using the expression "continuous" is the fact that God creates the world at every moment: at every instant of time, a "spurt" of monads is spread from God to the world, and such scattering guarantees, so to speak, that a continuum of monads, with their internal activities, the functioning of the world with pre-established harmony. 
From the creation and sustenance of the real world, composed of simple and derived monads (compound monads), the question arises as to whether there could be a logical possibility of other worlds being distinct from this, which one is our observable world. In fact, it is perfectly conceivable to God that He emanates or creates successively different monads of these that constitute the simple units of nature. It is also perfectly plausible that composite monads are other if God had conceived the world as different. But God conceived the world as it is because this world is the best of the possible worlds: the real world is the best world of possible worlds, and the other worlds doze in the thoughts of God, such as words that will never be said. It is to be noted that God has opted for this world, and not for another, endowed with the full exercise of his infinite Freedom, since it stems from the fact that God's Will is not determined by anything other than the full and infinite self- that God enjoys.

\section{A PROPOSAL FOR THE "CREATION" OF THE WORLD FROM LEIBNIZ AND CANTOR}

What follows in this section is a proposal for the metaphysical creation of the real world from the monadological scheme of Leibniz, as well as some elements of the Cantorian theory of sets $^{3}$. Let us begin with the hypothesis that God creates an infinite and enumerable quantity of monads. As it is known from Cantor's theory on transfinite numbers, under this hypothesis, the cardinality of the created monads are $\aleph_{0}$ (CANTOR, [1895], § 6).

This infinite quantity of monads would not emanate at any moment from God as Leibniz says, but in an instant, an instant or a purely metaphysical situation, an absolute beginning which occurs in the mind of God and whose phenomenological functioning is completely inaccessible to us to whom knowing the nature of this phenomenological context would imply in knowing the conscience of God, which in theory is impossible to man.

Given this initial and infinite quantity of monads, a "metaphysical configuration" is established in which all monads relate to God as Their creatures. What is being said here is that each monad, in some way, knows or feels in its inner activity that it, the monad in question, was created by God. In other words, God imprinted his mark on every monad, and they, the monads, tend to turn to God in their inner activity; and it is through this reminiscence or remembrance of God that the purposes of each monad are felt in the monadic internal activities. Metaphorically or allegorically speaking, all monads "reverence" God as their creator, and this reverence occurs consciously or merely with a feeling in which some teleology is perceived. In turn, God, the creator, sees Himself as the author of the monads, and out of love (an infinite Love which would be the superior activity which only God has), He relates Himself to all monads. It may even be said that God sees or perceives all monads as "creatures" that depend on Him, and thus establishes the bond of absolute Creator of all that exists. In this way, while the monads see themselves as creatures of God, God perceives himself as Creator, and it is His infinite and omnipotent Love - the guarantee of His absolute free and creative Will - that pervades each created monad. In this way, the

\footnotetext{
${ }^{3}$ Georg Cantor (1845-1918), a german mathematician, is considered the author of theory of sets. He introduces sistematically the study of infinite sets by means of his transfinite numbers, and the Works that will be used here as references are: CANTOR, G [1883]. Cantor's Grundlagen. IN: EWALD, W., ed. From Kant to Hilbert. A Source Book in the Foundations of Mathematics. Volume 1. Clarendon Press, Oxford, [1999], and CANTOR, G [1895-1897]. "Beiträge zur Begrundung der Transfiniten Mengelehre". Contributions to the Founding of the Transfinite Numbers. Dover Publications, New York, [1941].
} 
logical relations " $\mathrm{x}$ is created by $\mathrm{y}$ " and its inverse " $\mathrm{y}$ is the creator of $\mathrm{x}$ " are on the metaphysical basis of the creation of the world.

From this configuration that establishes itself with the relations mentioned above, the question arises of how God creates the real world. What is proposed here differs from the Leibnizian proposal, although it shares the conceptual basis of Leibniz. Since there are na infinite number of monads, God can group them in their totality a continuous number of times, and each unit of this arrangement is a possible world. It should be noted that each sequence of monads constitutes a possible world of null measure, since it consists of an infinite and enumerable quantity of monads ${ }^{4}$. Thus the possible worlds, just like the monads, are non-extensive beings who are situated in the mind of God as ready and actual thoughts. But how do the monadic arrangements that God performs in the unfathomable silences of His thoughts operate? Is there any rule by which God assembles monads to form worlds?

\section{A MATHEMATICAL SCHEME FOR THE "CREATION" OF THE WORLD}

Let' s start by considering that the Almighty God knows that He is the creator of everything. We can introduce here the hypothesis (Cantor-Leibniz hypothesis) that God created the world frorld comes from. The divine logos is the conscience that God has of this fact: He knows $\mathrm{He}$ is the creator of an infinite numbers of monads. Within an epistemic infinitary $\operatorname{logic}^{5}$, we can express this by means of the following expression (besides epistemic infinitary logic, we use also Cantor's theory of transfinite numbers in a very intuitive way):

1) $\boldsymbol{K}_{m_{\Omega}}\left(\wedge_{i \in \Theta_{1}} \mathbf{C}\left(\boldsymbol{m}_{\Omega}, \boldsymbol{m}_{i}\right)\right)$, where " $\boldsymbol{m}_{\mathrm{\Omega}}$ " is a name of God", and תis a very high cardinal number, such that $\Omega>\omega_{1}$

This formula above (the "Divine Logos") says that God knows He is the creator of an infinite and denumerable number of monads $\boldsymbol{m}_{\boldsymbol{i}}$, such that $\boldsymbol{i} \in \omega_{1}$.

From infinitary epistemic logic, we can derive the following conditional:

2) $K_{m_{\pi}}\left(\wedge_{i \in \omega_{1}} \mathbf{C}\left(m_{i n}, m_{i}\right)\right) \rightarrow \wedge_{i \in \omega_{1}} \mathbf{C}\left(m_{n}, m_{i}\right)$

2) expresses the fact that one can goes from God's Mind to reality: If God believes in something, then this something is. In some sense, the material implication in 2) has a metaphysical sense according as it represents that God's mind causes the infinitude of monads. In other words, the truth of the infinitary conjunction is caused by the fact that this conjunction lies in the God's Mind as a "Starting Divine Belief". This " Starting Divine Belief" causes in a relevant way the truth of the conjunction; if the antecedent was false, then the truth of the conditional could not be affirmed. Then, we are authorized to substitute

\footnotetext{
${ }^{4}$ In Measure Theory, an infinite and denumerable set has measure equals with null. On Measure Theory, see HALMOS, P.R [1950]: Measure Theory, Van Nostrand Company, Inc., New York.

${ }^{5}$ On Infinitary Epistemic Logic, see HEIFETZ, A, [1993], IN: https://pdfs.semanticscholar.org/a9b9/62f4e88d5701c279c7579142be3df08add32.pdf.

${ }^{6}$ Here one assumes that $\boldsymbol{m}_{\eta}$ is "a name of God", but not "the name of God". If one admits we are dealing with a translation of the name of God into set theory, then one could face the problem of attributing an end to the series of ordinal numbers, what is interdicted by Cantor's theory (see CANTOR, [1883], § 3 on).

In the expression. 1), $\omega_{1}$ is the first ordinal number of the third class of numbers, a number that can counted the continuous sets (see CANTOR, [1897], § 16). In the typical language of infinitary logic, this number is treated as a cardinal, not as an ordinal.
} 
the material implication by one one that represents metaphysical or ontological causation. Let's call this one by "»", and so 2) becomes the following metaphysical statement:

2') $K_{m_{Л}}\left(\Lambda_{i \in \Phi_{1}} \mathbf{C}\left(m_{Л}, m_{i}\right)\right) \geqslant \Lambda_{i \in \omega_{1}} \mathbf{C}\left(m_{Л}, m_{i}\right)$

We call " $\geqslant$ " metaphysical implication, and this notion will be very important from now on in this article.

From $\wedge_{i \in \Theta_{1}} \mathbf{C}\left(\boldsymbol{m}_{Л}, \boldsymbol{m}_{i}\right)$ we can reach the set $\boldsymbol{M}$ of all monads. It is easy to see that:

3) $\wedge_{i \in \Theta_{1}} \mathbf{C}\left(m_{Л}, m_{i}\right) \rightarrow \exists X\left(X=\left\{y / C\left(m_{Л}, y\right)\right\}\right)$.

The expression above can be replaced by its metaphysical version, namely:

4) $\wedge_{i \in \omega_{1}} \mathbf{C}\left(m_{\text {Л }}, m_{i}\right) \succcurlyeq \exists X\left(X=\left\{y / C\left(m_{\text {Л }}, y\right)\right\}\right)$

We can now give a name to this set $\boldsymbol{X}$, and this name will be $\boldsymbol{M}$, in such way that $\boldsymbol{M}$ $=\left\{\boldsymbol{m}_{1}, \boldsymbol{m}_{\mathbf{2}}, \ldots \boldsymbol{m}_{\mathrm{k}}, \ldots\right\}$. Of course, since the set $\boldsymbol{M}$ comes from the fact that God created all monads, we can express this metaphysically as:

5) $\wedge_{i \in \omega_{1}} \mathbf{C}\left(m_{Л}, m_{i}\right) \geqslant M=\left\{m_{1}, m_{2}, \ldots m_{\mathrm{k}}, \ldots\right\}$.

The only formal property that we associated to metaphysical implication is transitivity, and this association is very obvious in so far as we are considering this kind of implication as a translation into infinitary epistemic logic of the concept of causality. So we have:

6) $\boldsymbol{K}_{m_{Л}}\left(\wedge_{i \in \Theta_{1}} \mathbf{C}\left(m_{Л}, m_{i}\right)\right) \geqslant M=\left\{m_{1}, m_{2}, \ldots m_{\mathrm{k}}, \ldots\right\}$.

The conscience of God, His "Divine Logos", can chosse any monad, and this choice can occur for building possible worlds tha lie in God's Mind. One way to translate into logical language this God's choice could be by means of the following "Divine choice function":

7) $\bullet(x)=\varepsilon x \cdot \mathrm{C}^{-1}\left(m_{ת}, x\right)$.

The relation $\mathbf{C}^{-1}\left(m_{Л}, \boldsymbol{x}\right)$ is the inverse of $\mathbf{C}\left(\boldsymbol{m}_{Л}, \boldsymbol{x}\right)$. Since the former says that God created all monads, the latter tells us all monads was created by God: the first one express God as the creator of all monads (active voice), and the second one stress all monads as created by God (passive voice). The "epsilon operator"7 acting over $\boldsymbol{x}$ means that the function $\bullet(x)$ picks out randomly any monad that satisfies $\mathbf{C}^{-1}\left(m_{\pi} x\right)$. In some sense, this function tries to put into logical language the inextricable and mysterious choices of God.

With the aim of correlating this function to metaphysical implication, we can express the function $\bullet(x)$ by means of an arrow that explicitly shows what is the effect of applying $(x)$ on $\boldsymbol{M}$, namely:

8) $\quad M=\left\{m_{1}, m_{2}, \ldots m_{k}, \ldots\right\} \rightarrow_{\bullet}\left(1 m_{j \in \omega}\right.$

After $\omega$-times of applying $\bullet(x)$ (in other words, after an infinite and denumerable numbers of God's choice), we have the set:

9) $\boldsymbol{W}=\left\langle\boldsymbol{m}_{j}, \ldots\right\rangle$

$\boldsymbol{W}$ is an ordered, infinite and an denumerable set: $\boldsymbol{W}$ is a sequence, and we can identify it with a possible world.

\footnotetext{
${ }^{7}$ On "epsilon" operator, see WIRTH, C.P [2008]. "Hilbert's epsilon as an Operator of Indefinite Committed Choice". IN: Journal of Applied Logic. Vol. 6, Issue 3, pp. 287-317
} 
Since one can consider the applying of the $\boldsymbol{\bullet}(\boldsymbol{x})$ sucessively (more precisely, we can consider that God applies such function $\omega$-times on $\boldsymbol{M}$ ), it is easy to see that $\boldsymbol{W}$ is metaphysically caused by $\boldsymbol{M}$, namely:

10) $M=\left\{m_{1}, m_{2}, \ldots m_{\mathrm{k}}, \ldots\right\} \geqslant W$,

And by virtue of 6$)$ and the transitivity of metaphysical causation, we have:

11) $\boldsymbol{K}_{m_{\Pi}}\left(\wedge_{i \in \omega_{1}} \mathbf{C}\left(\boldsymbol{m}_{Л}, \boldsymbol{m}_{\boldsymbol{i}}\right)\right) \geqslant \boldsymbol{W}$.

It is interesting to notice that, from the set $\boldsymbol{M}$, a continuous number of possible worlds could be built in a strict and analagous way by which the set $\boldsymbol{W}$ is acquired: God chooses sucessively, from $\boldsymbol{M}, \aleph_{0}$ monads and these monadas are ordered by means their position in the set of choices of God. So, we have a continuous number of sequences of monads that are possible worlds ${ }^{8}$. Let us cal the set of all possible worlds by $\Pi$, and this set can be presented as:

12) $\Pi=\left\{W_{1}, W_{2}, \ldots, W_{\beta}, \ldots.\right\}$,

where $\beta$ is an adequate ordinal number that belongs to some Cantor's class of numbers ${ }^{9}$, and $\boldsymbol{W}_{\boldsymbol{m}} \neq \boldsymbol{W}_{\boldsymbol{n}}$ for $\boldsymbol{m} \neq \boldsymbol{n}$.

Since each $\boldsymbol{W}_{\boldsymbol{j}}$ comes from $\boldsymbol{M}$ by means of sucessive applications of the function $\bullet(x)$, we cam stress that:

13) $M \geqslant \Pi$,

And we'll have:

14) $K_{m_{\pi}}\left(\wedge_{i \in \Theta_{1}} \mathbf{C}\left(m_{-ת}, m_{i}\right)\right) \geqslant \Pi$

The set $\Pi$ is the space in God's Mind in which every possible world is located as a point: every possible world is a set whose measure is null, and they form some kind of Transcendent Space in God's Mind; and this transcendent space is caused by the Divine Logos.

One more thing must be added here: we are using the infinitary epistemic operator in a distributive way, that is, if one assumes that $\boldsymbol{K} \boldsymbol{p}$ and $\boldsymbol{p} \rightarrow \boldsymbol{q}$, then we can assert that $\boldsymbol{K}(\boldsymbol{p}$ $\rightarrow \boldsymbol{q}$ ) and $\boldsymbol{K q}$. Since we are admitting a strict analogy between epistemic operator and metaphysical causation, in such way that we can translated every infinitary epistemic statement into a new proposition in which metaphysical causation appears, then we can also affirm that:

\section{5) $\boldsymbol{K} \alpha$ and $\alpha \geqslant \boldsymbol{\beta}$, then $\boldsymbol{K}(\boldsymbol{\alpha} \geqslant \boldsymbol{\beta})$ and $\boldsymbol{K} \boldsymbol{\beta}$.}

In this way, every step from 1) up to 14) is presented in the "Divine logos", and more precisely this later must indentified with the following statement ("a more poweful expression. of the "Divine Logos"):

16) : $\boldsymbol{K}_{\boldsymbol{m}_{\mathrm{n}}}\left(\wedge_{i \in \omega_{1}} \mathbf{C}\left(\boldsymbol{m}_{\Omega}, \boldsymbol{m}_{i}\right) \wedge j \in \omega \Phi_{j}\right)$, where $\omega$ is the first cardinal number, and each $\Phi_{n}$ is a metaphysical consequence of

$$
\boldsymbol{K}_{m_{\mathrm{n}}}\left(\wedge_{i \in \Theta_{1}} \mathbf{C}\left(\boldsymbol{m}_{\mathrm{\Omega}}, \boldsymbol{m}_{i}\right)\right) \text {. }
$$

\footnotetext{
${ }^{8}$ If we consider each monad labelled with a natural number, then the quantity of possible worlds that God can create becomes the question concerninh how many functions are whose domain is the natural numbers; and the answer to this question is $2^{\mathrm{K}_{0}}=c$, where $c$ is the cardinal of continuous (see CANTOR, ibid, $\S 4$, [488]).

${ }^{9}$ Here we are admitting, as Cantor did, that every set can be counted or well-ordered, and this counting or wellorder is expressed by attributing an ordinal number to this set; and every number that is an expression. of some counting belongs to some class of ordinal numbers. (CANTOR, ibid, $\S 12$ on).
} 
So, by means of 16), we can assert that:

17) $K_{m_{\pi}}\left(\wedge_{i \in \Theta_{1}} C\left(m_{\Omega}, m_{i}\right) \wedge \Pi=\left\{W_{1}, W_{2}, \ldots, W_{\beta}, \ldots.\right\}\right)$.

From $\Pi$, God, in His Absolute Freedom, chooses one world (the best possible world, according to Leibniz) and, from this point in the transcendent space, built the real world, with its physical laws and space-time structure. But this passage from the best possible world to the real world will not be considered here, and it shall be a theme for another opportunity.

\section{BIBLIOGRAPHY:}

[1] CANTOR, G [1895-1897]. "Beiträge zur Begrundung der Transfiniten Mengelehre". Contributions to the Founding of the Transfinite Numbers. Dover Publications, New York, [1941];

[2] -------, [1883]. Cantor's Grundlagen. IN: EWALD, W., ed. From Kant to Hilbert. A Source Book in the Foundations of Mathematics. Volume 1. Clarendon Press, Oxford, [1999];

[3] CHAITIN G: Complexity and Leibniz, IN: https://www.cs.auckland.ac.nz/ chaitin/tenerife.html;

[4] HALMOS, P.R [1950]: Measure Theory, Van Nostrand Company, Inc., New York.

[5] HEIFETZ, A. "On Infinitary Epistemic Logic". [1993], IN: https://pdfs.semanticscholar.org/a9b9/62f4e88d5701c279c7579142be3df08add32.pdf.

[6] LEIBNIZ, G.W. La Monadologie, [1714]. English version IN:

[7] WIRTH, C.P [2008]. "Hilbert's epsilon as an Operator of Indefinite Committed Choice". IN: Journal of Applied Logic. Vol. 6, Issue 3, pp, 287-317. 